\title{
Empirical Study on the English Listening Learning Anxiety ${ }^{*}$
}

\author{
Xiaohui Xu \\ Qingdao University of Science and Technology, Qingdao, China
}

\begin{abstract}
College student always feel anxious in doing listening comprehension. Scholars have had research about the anxiety. But empirical research is rare, so this research is about the relationship between learning anxiety and study strategies, anxiety level of different students and so on. Conclusions are made based on the results.
\end{abstract}

Index Terms-listening comprehension, listening comprehension anxiety, learning strategies, cognitive strategies, socioaffective strategies

\section{INTRODUCTION}

In listening practice, different students have different learning anxiety. It is considered that most students with high anxiety level will have low learning efficiency. The occurrence of listening anxiety either in education settings or in communication settings most likely prevents listeners from comprehending the messages effectively. Hence we need to know whether students learned to actively and strategically participate in listening process, what causes anxious feelings to them and what strategies they can employ to cope with listening comprehension anxiety.

Classroom activities such as speaking and listening prove to be most anxiety-provoking and problematic for foreign language learners (Horwitz, Horwitz, \& Cope, 1986). It can be further assumed that the improvement in learners' learning performance might enhance their self-confidence in language learning. More self-confidence and self-fulfillment will probably result in less anxiety, fear or sense of frustration.

Take children's language acquisition as an example, it seems that children acquire their mother tongue in a very natural way, mainly depending on listening, repeating and talking.

\section{Definitions of Language Learning AnXiety}

Scovel (1978) defines anxiety as "a state of apprehension, a vague fear that is only directly associated with an object" (p.131). Spieberger (1983) describes anxiety from a neurobiological perspective, defining anxiety as "the subjective feeling of tension, apprehension, nervousness and worry associated with an arousal of the automatic nervous systems" (p.482). Horwitz, Horwitz and Cope (1986) examine anxiety related to foreign language learning and assert that foreign language learning anxiety is "a distinct complex of self-perceptions, beliefs, feelings and behaviors related to classroom language learning arising from the uniqueness of the language learning process" (p.126).

Bergoon (1983) pointed out that apprehension of communication varies according to the mode of communication. Therefore, in the late 1990s, the awareness of language-skill-specific anxiety generated a new trend in foreign language anxiety studies, which focused on speaking anxiety (Kitano, 2001), reading anxiety (Saito, Horwitz \& Garza, 1999), writing anxiety (Cheng, Horwitz \& Schallert, 1999), and listening anxiety (Vogely, 1998; Kim, 2000).

\section{A. The Effects of Anxiety on Language Learning}

Early researches on the effects of anxiety in foreign language learning fail to provide any clear-cut relationship between anxiety and learners' performance in a foreign language (Aida, 1994). For instance, Chastain (1975) studies the relationship between anxiety and course grades of three foreign language programs. The results indicate that there exists a significant negative correlation between course grades and test anxiety only in French audio-lingual class. In regular German and Spanish classes, however, students who experience a higher level of anxiety receive better grades than those with a lower level of anxiety.

\section{B. Controversies on the Role of Foreign Language Anxiety}

On the one hand, some researchers suggested that language anxiety was helpful or facilitating in some way. Because it motivated the learners to "fight" the new learning task and geared the learners emotionally for approach behavior (Ellis, 1994). Kleinmann (1977) studied the Spanish-speaking and Arabic-speaking ESL students and found facilitating anxiety correlated with students' oral production of difficult English structures.

\footnotetext{
* This paper is the partial result of Qingdao University of Science and Technology teaching research project in 2013 "The action research of college English listening class from the perspective of circulation."
} 
On the other hand, most language researchers claimed that anxiety played a negative part in SLA (Chastain, 1975). It caused the learners to "flee" the learning task in order to avoid the sources of anxiety (Ellis, 1994). Bailey (1983) explored the correlation between anxiety and learners' performance and concluded that a high level of anxiety could have adverse effects on students' foreign language performance. Depending on the individual, anxious foreign language learners may express their feelings through avoidance behavior, such as skipping language class, failing to prepare for class or avoiding eye contact with the instructor.

Chen Yanjun (2005) investigated the relationship between foreign language listening anxiety and listening strategy in his dissertation for Master's degree. He found students' listening anxiety had a significant negative correlation with listening strategies, especially with cognitive strategies. However, it is still questionable whether the causation relationship between the two existed. It is also likely that students' listening anxiety prevent them from effectively employing listening strategies.

In this study, the author will continue to test the existence of listening anxiety and contrive to find out the effective ways to lower students' anxiety.

So we have the following questions to answer:

1) What is the state of listening comprehension anxiety experienced by non-English majors?

2) Is there any significant correlation between listening comprehension anxiety and use of listening learning strategies?

3) Is there any significant difference in listening comprehension anxiety levels and use of listening learning strategies between male learners and female learners?

\section{EMPIRICAL STUDY AND THE RESULTS}

\section{A. Subjects}

Subjects participating in the present study were 186 second-year students of two intact classes from the College of Gardening at Southwest China Agricultural University. Most of them have been exposed to listening comprehension class ever since they were in junior middle school even when in primary school. By the time of their second year in college, these students might have developed their own way of dealing with listening exercises and may probably have consciously or unconsciously employed a series of strategy. Eight of the 186 students failed to properly finish both of the two questionnaires, were eliminated from analysis. Finally the participants selected for this study were 178 students, including 96 male students and 82 females.

\section{B. Design of the Questionnaires}

First they are asked the following questions for a pre-survey, and then do the questionnaire. According to the needs of this study, the oral interviews focused on the following questions:

(1) What is your reason for studying English?

(2) What has influenced your listening most?

(3) Do you feel anxious when listening to English? If yes, can you describe what your listening anxiety is like?

(4) What do you think has caused your discomfort and anxiety in listening to English?

(5) What measures do you usually adopt to make yourself less stressful while listening to English? And what do you think the teachers could do to help you to debilitate anxiety?

The sources of this questionnaire could be located in other influential scales like foreign language Classroom Anxiety Scale (Horwitz, Horwitz \& Cope, 1986). Some adaptations and modifications were made so as to ensure the questionnaire could reflect Chinese English learners' actual feelings in listening activities. In addition, the present researcher supplemented a couple of items, drawing on her own experiences with English teaching.

This questionnaire consisted of 14 items written in Chinese version to make sure that all the students can fully understand. Each item was to be answered on a 5-point Likert scale, including "strongly agree", "agree", "neither agree nor disagree", "disagree", "strongly disagree".

The questions about anxiety level include:

1. I am confident when listening to the tapes.

2. I like English listening class.

3. 1 like all kinds of listening materials, such as tapes, songs, news, etc.

4. I feel relaxed when having English listening class, and I am satisfied with my listening abilities.

5. I always answer questions in listening class for I don not fear the negative comments of the teacher and student.

6. My brain will be in a mess when I listen to the tape, so I can not remember the content.

7. I will be fearful when I know that I will listen to an English tape.

8. I will feel nervous when I find out that the topic of the tape is not familiar.

9. I think English learning is the hardest part of study.

10. I will feel anxious when the speed of the passage is too fast.

11. I always think that the other students study English better than me.

12. I always feel anxious when I meet the long sentences with complicated grammar.

13. When I heard something about the western culture, I may feel nervous because I am not familiar with it. 
14. When I miss something in listening practice I will feel nervous.

15. When I meet someone who has weird accent, I will not like to listen any more.

For question 1 to 5 , the five responses of such items were assigned the value of 1, 2, 3, 4 and 5 respectively. For the rest of the 14 items, whose statements indicated that a learner was anxious, stressed or distracted, responses were assigned the value of 5, 4, 3, 2 and 1 respectively.

Another vital questionnaire was the English Listening Learning Strategy (ELLS), used for measuring the frequency of listening learning strategy use. The design of ELLS counted on many sources, including the Strategy Inventory for Language Learning (Oxford, 1990) and some listening comprehension strategies obtained from other researchers' investigations.

It was composed by 15 strategy items, including 11 cognitive strategies items, 4 socioaffective ones. In choosing the strategy items, a framework of three broad categories was adopted. Cognitive strategy items cover note-taking, auditory presentation, summarization and so on. Socioaffective strategy items involved self-encouragement, seeking cooperation from others, and direct way of lowering anxiety. Still some subtle modifications were made so that the questionnaire can better reflect the situations of Chinese English learners. Meanwhile the questionnaire was translated into Chinese so as to guarantee greater accuracy of the results, especially with the less proficient students. Like the design of Listening Comprehension Anxiety Scale (LCAS), each item in the ELLS were to be answered on a 5-point Likert scale, ranging from "never use", "some times use", "half of the time use", "most of the time use" and "always use".

\section{Results}

\section{Listening Anxiety Scores of All the Subjects}

Since the LCAS consisted of 18 question items and the score of each item ranged from 1 to 5 points, the potential score of each student's anxiety should range from 18 to 90 points.

As Table 3.1 revealed, among the 178 subjects, the maximum score and the minimum score of LC anxiety were 84 and 25 respectively. The low anxiety level group consisted of 39 students whose anxiety scores ranged from 25 to 46 , while the medium anxiety level group included 91 students whose anxiety scores varied from 47 to 66 . As for the high anxiety level group, it was composed by 48 students whose anxiety scores were between 67 and 84 .

TABLE 3-1

STUDENTS' LISTENING ANXIETY SCORES

\begin{tabular}{|l|l|l|l|l|}
\hline & N & Mean & Minimum & Maximum \\
\hline & 178 & & & \\
\hline High anxiety group & 48 & 71.6 & 67 & 84 \\
\hline Medium anxiety group & 91 & 52.9 & 47 & 66 \\
\hline Low anxiety group & 39 & 37.2 & 25 & 46 \\
\hline
\end{tabular}

The Post-hoc LSD tests of listening comprehension (LC) anxiety scores for each group indicated that the differences between any of the two anxious levels were significant, though the intermediate anxious group remarkably outnumbered the other two levels.

\section{Relationship between LC Anxiety and Strategies}

TABLE 3-2

COGNITIVE STRATEGY ITEMS SHOWING SIGNIFICANT NEGATIVE CORRELATIONS WITH LC ANXIETY

\begin{tabular}{|c|c|c|c|c|c|c|c|c|c|c|c|}
\hline \multirow[t]{2}{*}{ Anxiety } & \multicolumn{11}{|c|}{ Cognitive strategy items } \\
\hline & 1 & 2 & 3 & 4 & 5 & 6 & 7 & 8 & 9 & 10 & 11 \\
\hline Pearson correlation & -.278 & -.398 & -.367 & -.212 & -.478 & -.398 & -.211 & -.263 & -.287 & -.243 & -.209 \\
\hline Sig. & .001 & .000 & .000 & .007 & .000 & .001 & .025 & .006 & .003 & .016 & .022 \\
\hline
\end{tabular}

The questions include:

1. Guessing the meaning of an unfamiliar word from the context.

2. Skipping the unknown word and going on with listening task.

3. Distinguishing the implications of the same sentence spoken in different intonations.

4. Applying different methods to different types of listening materials.

5. Remembering the main ideas read in English version without doing translation.

6. Focusing on the overall meanings rather than on every single word or sentence.

7. Summarizing the main ideas from what was caught in listening contents.

8. Taking notes of an event with the key words like the time, the person and the process etc.

9. Using abbreviated verbal, numeral, or graphic forms to take notes.

10. Listening to the contents failed to understand in class and trying to find out reasons.

11. Accumulating frequently used words and expressions in listening materials.

TABLE 3-3

SOCIOAFFECTIVE STRATEGY ITEMS SHOWING SIGNIFICANT NEGATIVE CORRELATIONS WITH LC ANXIETY

\begin{tabular}{|l|l|l|l|l|}
\hline \multirow{2}{*}{ Anxiety } & \multicolumn{4}{|l|}{ Socioaffective strategy items } \\
\cline { 2 - 5 } & 1 & 2 & 3 & 4 \\
\hline Pearson correlation & -.175 & -.235 & -.329 & -.358 \\
\hline
\end{tabular}




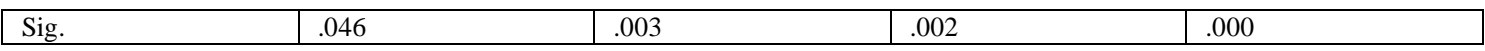

Socioaffective strategy items showing significant negative correlations with listening comprehension anxiety. They are the followings:

1. Comforting oneself by saying that it is unnecessary to catch everything in a listening task when failing to grab some words or sentences.

2. Telling oneself not to worry when the listening task are unfamiliar and difficult.

3. Encouraging oneself by saying that one will do well in the listening task.

4. Relaxing oneself by breathing deeply when feeling nervous before listening.

Then why did they demonstrate such significant differences in listening anxiety levels? The individual differences such as intrinsic characters, use of learning strategies, self-beliefs about listening comprehension and commitment to listening tasks most likely contributed to the great differences in learners' listening anxiety. All these factors might more or less exert influence on learners' listening anxiety.

\section{Gender Differences in Learners' Listening Anxiety Levels}

As for the difference in LC anxiety level between male students and female students, it could be detected via t-test. From Table 4.4, we could see that although the mean LC anxiety score of male students was higher than that of female students, the mean difference wasn't statistically significant $(t=1.164, p=.176)$. In other words, the male students and the female students experienced the similar degree of LC anxiety.

TABLE 3-4

RESULTS OF T-TESTS FOR THE GENDER DIFFERENCE IN LC ANXIETY SCORES

\begin{tabular}{|l|l|l|l|l|}
\hline Gender & $\mathrm{N}$ & Mean & T-value & P \\
\hline Male & 96 & 57.38 & 1.164 & .176 \\
\cline { 1 - 2 } Female & 82 & 55.65 & & \\
\hline
\end{tabular}

Kitano (2001) investigated the anxiety of college learners of Japanese and found that male students felt higher anxiety than their female counterparts when they perceived their spoken Japanese less competent than that of others.

\section{Summary}

According to the pre-survey, students' status of study is quite obvious. Most of them has the LC anxiety more or less.

In general, the above results revealed that students' use of listening learning strategies had a significant negative correlation with listening anxiety. Cognitive strategy showed strong correlations with listening anxiety than the socioaffective category. More specifically, 11 cognitive items and 4 socioaffective items were significantly and negatively correlated with listening anxiety.

As for socioaffective strategy category, however, no significant differences were found between any of the anxiety levels, though they showed a marginally significant negative correlation with anxiety levels.

\section{CONCLUSIONS AND SUGGESTIONS}

\section{A. Conclusion}

The above discussions centered on detailed interpretations concerning the research questions including: the correlations between LC anxiety and the use of listening strategies, differences in the use of individual strategy items among the three anxiety levels and gender difference in LC anxiety level and use of listening strategies. With the previous results and discussions in hand, conclusions of this research could be drawn.

The analysis of 178 subjects' data is as following:

1) In general, the non-English majors under investigation experience considerably high level of LC anxiety.

2) Students' LC anxiety has a significant negative correlation with their use of listening learning strategies, especially with their use of cognitive strategies.

3) The cognitive strategy category show significant difference in use across the three anxiety levels, while with socioaffective strategy no significant differences in use are found across the three anxiety levels.

4) There exist significant differences in the use of 15 individual strategy items among the three anxiety levels, especially between students at low anxiety level and those at high anxiety level.

5) There exists no significant difference in LC anxiety level between male and female learners. Female students demonstrate significant differences in the use of cognitive strategies from male students.

\section{B. Suggestions}

The finding that listening anxiety is negatively correlated with use of listening learning strategies implies that use of effective listening strategies may play an important role in lowering listening anxiety. Hence teachers should put strategy instruction into regular classroom activities in an explicit way. For example, teachers can help students be conscious of the background knowledge of the topic, knowledge about the type of text and relevant cultural information. Teachers should also teach students how to make predictions on the basis of the assigned listening tasks and questions.

In light of the negative correlation between listening anxiety and use of listening learning strategies, further research is needed to examine the effects of listening strategies use on listening anxiety. In doing so, we can better understand to 
what extent listening strategies can help students reduce listening anxiety.

First, teachers should acknowledge the existence of listening anxiety and consider the possibility that listening anxiety is responsible for the students' poor performance before attributing it solely to the low levels of language aptitude or weak motivation. Then they can explain to the students the fact that listening anxiety is shared by nearly everyone, most of the other students experience similar fear of failure. Teacher's sympathetic attitude towards the problems and fear of students would motivate them to overcome their own anxiety.

Second, English teachers should help students build up self-confidence. The results of this study show that, for Chinese university students, self-confidence is a most important determination of the listening anxiety and actual performance. Self-confidence is an attitude which allows individuals to have positive views of themselves and their abilities. People who are confident trust their own abilities, have a general sense of control in their lives, and believe that, within reason, they will be able to do what they wish, plan and expect. People who are not self-confident depend excessively on the approval of others. They tend to avoid taking risks because they fear failure and generally do not expect to be successful. Teachers can help students by bring students into discussions of the language learning listening process, ensuring that teaching goals are appropriate and attainable, helping students recognize that they can be successful.

Increasing opportunities for students to experience small successes will also be a way to help reduce students' listening anxiety. During the process, teachers need not correct every error the students make. Vogely (1998) suggested using appropriate practice exercises tailored for each skill level, as a means of permitting students to experience success.

Besides, positive feedback and continued encouragement may lower the level of the students' anxiety and frustration and enable them to develop greater self-confidence.

Third, considering male students have higher anxiety when listening, and use less listening strategies, improving males' engagement in listening remains essential in order to ensure that all students realize their potential. For instance, male students can be organized to form different English listening-interest groups consisting of mere roommates. Each group member is encouraged to share his views or difficulties with others based on his comprehension of the listening materials, then seminar can be held each week to exchange their experience, reactions and comments after listening. All this could be done in a friendly, relaxed, helpful and harmonious atmosphere. In addition lectures concerning successful listening strategies should be accompanied to solve the problems encountered.

Fourth, regarding the facilitating effect of listening anxiety, in order to make listening less stressful, English teachers need to do more exploration of facilitating anxiety level, especially of strategy training. From the interview with the participants, the author has learned that their lack of effective listening strategies is one important cause for them to feel frustrated and nervous in listening. Even though some language teachers mentioned that in the students' textbooks some strategies about listening have been introduced, but these are not enough. There is no systematic, comprehensive and practicable instruction about listening strategies.

Fifth, in listening teaching, teachers should not only to improve the English proficiency levels of but also introduce the history, geography and customs etc. of English speaking knowledge in the learner's minds countries and those of our own culture. Background is in the memory and they need to be activated, so in listening comprehension classes, teachers should help students to make full use of the information received to mobilize the schema or background knowledge stored in their minds, so that they can process the information thoroughly. So listening to passages of all types is useful. In addition, teachers can encourage students to get the knowledge of the world including the cultural knowledge of their own after class, such as taking lectures, distributing leaflets on this kind of knowledge. Furthermore, it is necessary to read in large amount after class. By these means, students accumulate such kind of knowledge consciously, broaden their views and then become sensitive to intercultural communications.

\section{Further Study}

First of all, the sample of the present study was limited to the sophomores of non-English majors in Qingdao University of Science and Technology. Therefore, the present author recommends that in future studies, the scope of the participants should be expanded to the students of English majors or to the students from other universities so as to expend the current findings and deepen our understandings of the phenomenon of listening anxiety.

Secondly, because time is limited, the present study is only static and it does not trace the participants' development processes. However, anxiety may vary by changing experience and language proficiency. Therefore, in the future, longitudinal studies need to be undertaken for a better understanding of the variations of the foreign language learners' listening anxiety.

Thirdly, using only one listening test of CET-4 may not be sufficient to accurately learners' listening proficiency. Therefore, future study should use multiple measurements for English listening proficiency.

Fourthly, further research can also look into the potential interactions between listening anxiety and other individual characteristics, such as self-confidence, beliefs about listening comprehension learning and commitment to extracurricular listening training.

In addition, in order to decrease the test anxiety of listening in Chinese context, both teachers and students could adopt a proper attitude towards test. It is only a means of assessing students' recent achievement rather than their competence. So we should make further study in the future consistently to get more confirmed results. 


\section{REFERENCES}

[1] Aida, Y. (1994). Examination of Horwitz, Horwitz and Cope's Construct of Foreign Language Anxiety: the Case of Students of Japanese. The Modern Language Journal, 78: 155-167.

[2] Bailey, K. M. (1983). Competitiveness and Anxiety in Adult Second Language Learning: Looking at and Through the Diary Studies. In H. W. Seliger \& M. H. Long (Eds.), Classroom-Oriented in Second Language Acquisition (pp. 67-102). Rowley, MA: Newbury House Publisher, Inc.

[3] Bergoon, J. \& Hale, J. L. (1983). A Research Note on the Dimension of Communication Reticence. Communication Quarterly, 31, 238-248.

[4] Chastain, K. (1975). Affective and Ability Factors in Second-language acquisition. Langue Learning, 25: 153-161.

[5] Chen Yanjun. (2005). A Study on Foreign Language Listening Anxiety of Chinese University Non-English Majors. Unpublished M. A. Dissertation. Changsha: College of Hunan Normal University Studies.

[6] Cheng, Y. S., Horwitz, E. K. \& Schallert, D. L. (1999). Language Anxiety: Differentiating Writing and Speaking Components. Language Learning, 49: 417-446.

[7] Ellis, R. (1994). The Study of Second Language Acquisition. Shanghai: Shanghai Foreign Language Education Press.

[8] Horwitz, E. K., Horwitz, M. B., \& Cope J. (1986). Foreign Language Classroom Anxiety. The Modern Language Journal, 70 : $125-132$.

[9] Kim, Joo-hae. (2000). Foreign Listening: A study of Korean Students Learning English. Unpublished Ph. D. Dissertation. Austin: University of Texas.

[10] Kitano, K. (2001). Anxiety in the College Japanese Language Classroom. The Modern Language Journal, 85: 125-132.

[11] Kleinmann, H. H. (1977). Avoidance Behavior in Adult Second Acquisition. Language Learning, 27, 93-107.

[12] Oxford, R. (1990). Language Learning Strategies: What Every Teacher Should Know. New York: Newbury House.

[13] Saito, Y., Horwitz, E. K. \& Garza, T. J. (1999). Foreign Language Reading Anxiety. The Modern Language Journal, 83, 202-218.

[14] Scovel, T. (1978). The Effects of Affect on Foreign Language Learning: A Review of the Anxiety Research. Language Learning, 28, 129-142.

[15] Spieberger, C.D. (1983). Manual for the State-Trait Anxiety Inventory. Palo Alto, CA: Consulting Psychologists Press.

[16] Vogely, A. J. (1998). Listening Anxiety: Sources and Solutions. Foreign Language Annals, 31, 67-80.

Xiaohui Xu was born in Zibo, China in 1977. She received her M.A. degree in Foreign Linguistics and Applied Linguistics from Ocean University of China in 2010.

She is currently a lecturer in the School of Foreign Languages, Qingdao University of Science and Technology, Qingdao, China. Her research interests include Second Language Acquisition and English teaching. 